\title{
Assessment of competence in video-assisted thoracoscopic surgery lobectomy: A Danish nationwide study
}

\author{
René Horsleben Petersen, MD, PhD, ${ }^{\mathrm{a}}$ Kirsten Gjeraa, $\mathrm{MD}, \mathrm{PhD},{ }^{\mathrm{b}}$ Katrine Jensen, $\mathrm{MD}, \mathrm{PhD},{ }^{\mathrm{a}}$ \\ Lars Borgbjerg Møller, MD, ${ }^{\mathrm{c}}$ Henrik Jessen Hansen, $\mathrm{MD},{ }^{\mathrm{a}}$ and Lars Konge, MD, $\mathrm{PhD}^{\mathrm{b}}$
}

\section{ABSTRACT}

Background: Competence in video-assisted thoracoscopic surgery lobectomy has previously been established on the basis of numbers of procedures performed, but this approach does not ensure competence. Specific assessment tools, such as the newly developed video-assisted thoracoscopic surgery lobectomy assessment tool, allow for structured and objective assessment of competence. Our aim was to provide validity evidence for the video-assisted thoracoscopic surgery lobectomy assessment tool.

Methods: Video recordings of 60 video-assisted thoracoscopic surgery lobectomies performed by 18 thoracic surgeons were rated using the video-assisted thoracoscopic surgery lobectomy assessment tool. All 4 centers of thoracic surgery in Denmark participated in the study. Two video-assisted thoracoscopic surgery experts rated the videos. They were blinded to surgeon and center.

Results: The total internal consistency reliability Cronbach's alpha was 0.93 . Inter-rater reliability between the 2 raters was Pearson's $r=0.71(P<.001)$. The mean video-assisted thoracoscopic surgery lobectomy assessment tool scores for the 10 procedures performed by beginners were 22.1 (standard deviation [SD], 8.6) for the 28 procedures performed by the intermediate surgeons, $31.2(\mathrm{SD}, 4.4)$, and for the 20 procedures performed by experts $35.9(\mathrm{SD}, 2.9)(P<.001)$. Bonferroni post hoc tests showed that experts were significantly better than intermediates $(P<.008)$ and beginners $(P<.001)$. Intermediates' mean scores were significantly better than beginners $(P<.001)$. The pass/fail standard calculated using the contrasting group's method was 31 points. One of the beginners passed, and 2 experts failed the test.

Conclusions: Validity evidence was provided for a newly developed assessment tool for video-assisted thoracoscopic surgery lobectomy (video-assisted thoracoscopic surgery lobectomy assessment tool) in a clinical setting. The discriminatory ability among expert surgeons, intermediate surgeons, and beginners proved highly significant. The video-assisted thoracoscopic surgery lobectomy assessment tool could be an important aid in the future training and certification of thoracic surgeons. (J Thorac Cardiovasc Surg 2018;156:1717-22)

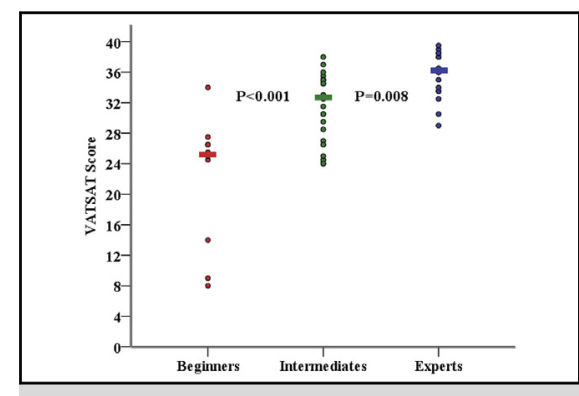

Box-and-whiskers plot showing relation between the experience level of the thoracic surgeons and the VATSAT score.

\section{Central Message}

Validity evidence using Messick's framework was provided for a newly developed specific assessment tool (VATSAT) allowing for structured and objective assessment of VATS lobectomy competence.

\section{Perspective}

In the surgical societies around the world, there is an increasing focus on ensuring continuous education and credentialing of surgical skills according to stringent quality criteria. This study provides validity evidence for a newly developed specific assessment tool for VATS lobectomy (VATSAT), which may be an important aid the future training and certification of thoracic surgeons.

See Editorial Commentary page 1723.

\footnotetext{
From the a Department of Cardiothoracic Surgery, Copenhagen University Hospital, Rigshospitalet, Copenhagen, Denmark; ${ }^{\mathrm{b}}$ Copenhagen Academy for Medical Education and Simulation (CAMES), University of Copenhagen and the Capital Region of Denmark, Copenhagen, Denmark; and ${ }^{\mathrm{c}}$ Department of Cardiothoracic Surgery, Aalborg University Hospital, Aalborg, Denmark.

Received for publication Jan 4, 2018; revisions received April 5, 2018; accepted for publication April 7, 2018; available ahead of print May 15, 2018

Address for reprints: René Horsleben Petersen, MD, PhD, Department of Cardiothoracic Surgery, Copenhagen University Hospital, Rigshospitalet, Inge Lehmannsvej 7, 2100 Copenhagen, Denmark (E-mail: rene.horsleben.petersen@regionh.dk). $0022-5223 / \$ 36.00$

Copyright (c) 2018 by The American Association for Thoracic Surgery https://doi.org/10.1016/j.jtcvs.2018.04.046
}

Lung cancer is the most deadly cancer worldwide, and it is estimated that 1.7 million people died of lung cancer in 2015. ${ }^{1}$ Surgical resection remains the mainstay in curing localized lung cancer. ${ }^{2}$ Traditionally, the approach for

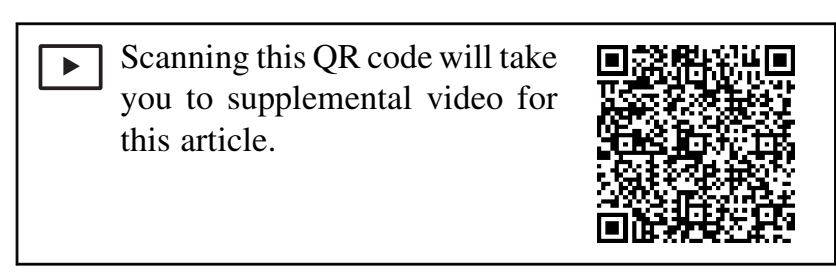




\section{Abbreviations and Acronyms \\ ANOVA $=$ analysis of variance \\ SD $=$ standard deviation \\ VATS $=$ video-assisted thoracoscopic surgery \\ VATSAT $=$ video-assisted thoracoscopic surgery \\ lobectomy assessment tool}

surgical resection has been a thoracotomy. Video-assisted thoracoscopic lobectomy was introduced 25 years ago and is now the recommended approach for early-stage lung cancer. ${ }^{3}$ The potential benefits include less postoperative pain, shorter length of stay, better quality of life, ${ }^{4}$ better shoulder function, fewer complications, ${ }^{5}$ better tolerance of adjuvant chemotherapy, ${ }^{6}$ and perhaps even improved survival. ${ }^{7}$ Despite the obvious advantages of this approach, the adoption of the procedure has been slow. Performing a video-assisted thoracoscopic surgery (VATS) lobectomy requires a different set of skills compared with thoracotomy, such as overcoming the fulcrum effect when operating through ports and transforming the 2-dimensional images on the monitor into a 3-dimensional understanding. The potential risk of hemorrhage due to injury of the pulmonary artery requires experience and skills to handle in a VATS scenario without causing a catastrophic intraoperative complication. ${ }^{8}$ Several articles have addressed the issue of learning how to perform a VATS lobectomy. ${ }^{9}$ Recommendations so far have been to attend courses in VATS lobectomy, visit centers with a substantial experience in VATS lobectomy, and then begin in a stepwise manner preferably supervised by an experienced VATS surgeon (mentor) until competency was achieved. ${ }^{10}$ Traditionally, competency has been established on the basis of numbers of procedures performed, and experts in VATS surgery have proposed 50 VATS lobectomies as a threshold for competency. ${ }^{11,12}$ However, procedural experience does not ensure competence. ${ }^{13}$ Specific assessment tools have been developed to allow for structured and objective assessment of competence, but it is essential that these provide valid measures. ${ }^{14}$ The aim of this study was to provide validity evidence for a newly developed video-assisted thoracoscopic surgery lobectomy assessment tool (VATSAT). ${ }^{15}$

\section{MATERIALS AND METHODS \\ Data Collection}

An independent investigator (K.G.) recorded the videos from VATS lobectomies performed at all 4 thoracic centers in Denmark. Only unedited videos were used for assessment, and the surgeons did not have access to their videos. The investigator was present in the operating room throughout the operations to make detailed notes of who performed the single parts of the procedure. The surgeons were divided into 3 groups according to their previous experience in VATS lobectomy at the beginning of the study. Surgeons having performed between 1 and 49 VATS lobectomies were grouped as beginners. Surgeons having performed between 50 and 499
VATS lobectomies were labeled as intermediates. Surgeons having performed 500 VATS lobectomies or more were labeled as experts. Two independent thoracic surgeons with a solid experience in VATS lobectomy rated the videos using a newly developed VATS Lobectomy Assessment Tool (VATSAT) for technical scoring of VATS lobectomies. ${ }^{15}$ VATSAT score was developed using the Delphi method as a structured process for collecting and distilling knowledge from a group of international experts in VATS lobectomy. ${ }^{15,16}$ The 8 items in the VATSAT are (1) localization of tumor and other pathological tissue, (2) dissection of the hilum and veins, (3) dissection of the arteries, (4) dissection of the bronchus, (5) dissection of lymph nodes, (6) retrieval of lobe in bag, (7) respect for tissue and structures, and (8) technical skills in general. Each item was rated 1 to 5 , where 5 was the best score, giving a minimum score of 8 and a maximum score of 40 . The 2 raters were blinded to the surgeon and the center where the procedure was performed. Video 1 shows the use of VATSAT.

\section{Validity Evidence}

Validity evidence was established on the basis of Messick's framework $^{17}$ as recommended by the Standards of Educational and Psychological Testing ${ }^{18}$ with the following 5 major sources of evidence:

Content: Content validity for the VATSAT tool was established in a previous study from our research group. ${ }^{15}$ The content was thoroughly evaluated in 3 rounds by a large group of internationally recognized VATS lobectomy experts using the Delphi method. ${ }^{16}$

Response process: The 2 raters were carefully instructed on how to rate the videos using the VATSAT tool. Both raters rated all videos independently according to their instructions.

Internal structure: The degree to which the items in the VATSAT fit the underlying construct was reported by internal consistency reliability and inter-rater reliability.

Relations to other variables: VATSAT's discriminatory ability among beginners, intermediates, and experts was calculated using mean scores and analysis of variance (ANOVA) with Bonferroni post hoc tests. The correlation coefficient between the number of VATS lobectomies performed (expressed in the logarithmic scale) and the VATSAT score was calculated.

Consequences: Impact of the VATSAT scores was assessed using the contrasting group's method (a method to identify a cut score based on overlapping frequency distributions of 2 groups) to calculate the mean pass/fail VATSAT score and explore false-positives and false-negatives.

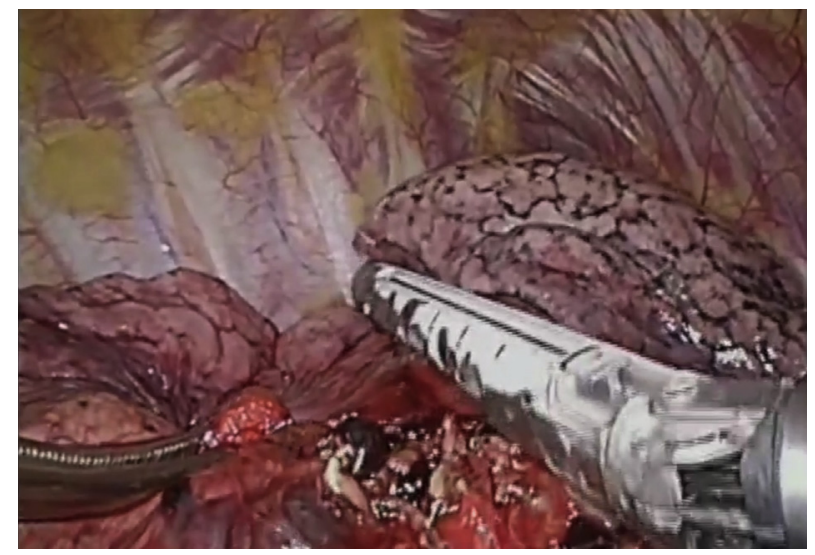

VIDEO 1. Right lower VATS lobectomy rated using the VATSAT tool. Video available at: https://www.jtcvs.org/article/S0022-5223(18)31030-4/ fulltext. 
TABLE 1. Patient characteristics and surgical outcome

\begin{tabular}{lc}
\hline \multicolumn{2}{c}{ Patient characteristics, $\mathbf{n}=\mathbf{5 8}$} \\
\hline Age, y & Mean (SD) \\
\hline Gender & $70(8.2)$ \\
$\quad$ Male/female & $29 / 29$ \\
$\mathrm{FEV}_{1}, \%$ & $89(22.0)$ \\
Tumor size, mm & $26(11.9)$ \\
Type of lobectomy & \\
Lower lobes & $21(36 \%)$ \\
Middle lobe & $5(9 \%)$ \\
Upper lobes & $30(52 \%)$ \\
Bilobectomy & $2(3 \%)$ \\
\hline \multicolumn{2}{c}{ Surgical outcome, $\mathbf{n}=\mathbf{5 8}$} \\
\hline
\end{tabular}

$\overline{S D}$, Standard deviation; $F E V_{l}$, forced expiratory volume in 1 second; $I Q R$, interquartile range.

\section{Ethics}

An application was send to the local ethics committee (Journal No. H-16041772), but was waived. According to Danish law, educational studies do not need approval. Written and oral informed consent were obtained from all participating surgeons.

\section{Statistics}

Cronbach's alpha, Pearson's r, and ANOVA with post hoc analysis were calculated using IBM SPSS statistics version 23 (IBM, New York, NY).

\section{RESULTS}

From December 19, 2016, to July 5, 2017, 60 VATS lobectomies performed at the 4 thoracic centers in Denmark were video recorded and enrolled in the study. Eighteen thoracic surgeons performed the 60 procedures. Their personal experience in VATS lobectomy ranged from 9 to 1200 procedures completed at the beginning of data collection. Fifteen of the 18 surgeons were specialists in cardiothoracic surgery, and the remaining 3 surgeons were senior residents in cardiothoracic surgery. A specialist supervised all procedures $(n=8)$ performed by residents. If the supervisor had to interfere in the procedure and perform part of it, the investigator noted this and the corresponding item received the minimum score of 1 point. Two VATS lobectomies were converted to open surgery during the procedure. They were excluded from the study, because the raters were unable to use the assessment tool (VATSAT), which is constructed for VATS specific issues only. The remaining 58 VATS lobectomies were included in the final data analysis. Patient characteristics and surgical outcome are listed in Table 1.

Internal structure: The total internal consistency reliability Cronbach's alpha was 0.93 with a value of 0.89

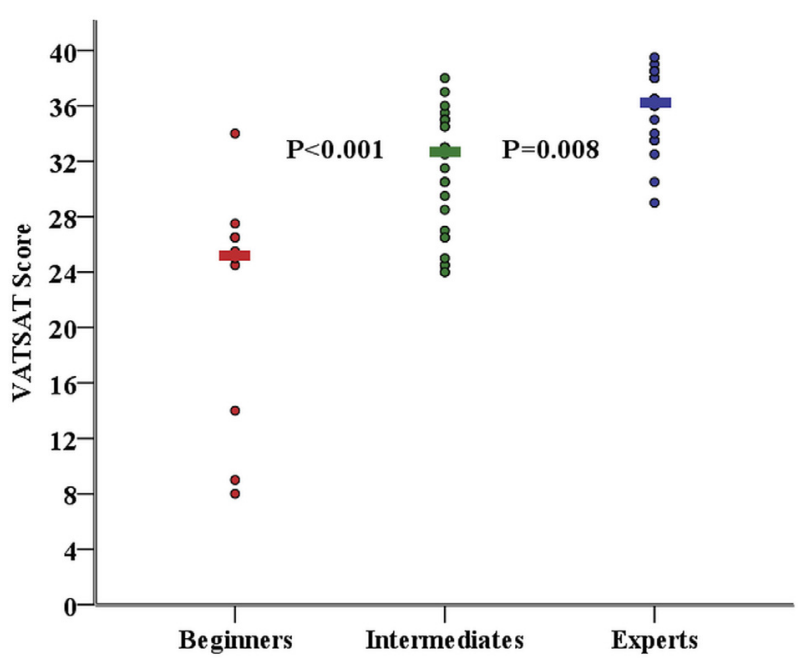

FIGURE 1. Box-and-whiskers plot showing relation between the experience level of the thoracic surgeons and the VATSAT score. Beginners $\mathrm{n}=10$ procedures, $\mathrm{n}=6$ surgeons (red dots), intermediates $\mathrm{n}=28$ procedures, $\mathrm{n}=9$ surgeons (green dots), experts $\mathrm{n}=20$ procedures, $\mathrm{n}=3$ surgeons (blue dots). Colored bar: median VATSAT score. VATSAT, Video-assisted thoracoscopic surgery lobectomy assessment tool.

for rater 1 and 0.91 for rater 2 . Inter-rater reliability between the 2 raters was Pearson's $\mathrm{r}=0.71(P<.001)$.

Relation to other variables: The mean VATSAT score for the 10 procedures performed by beginners were 22.1 (standard deviation [SD], 8.6; range, 8.0-34.0), for the 28 procedures performed by the intermediate surgeons 31.2 (SD, 4.4; range, 24.0-38.0), and for the 20 procedures

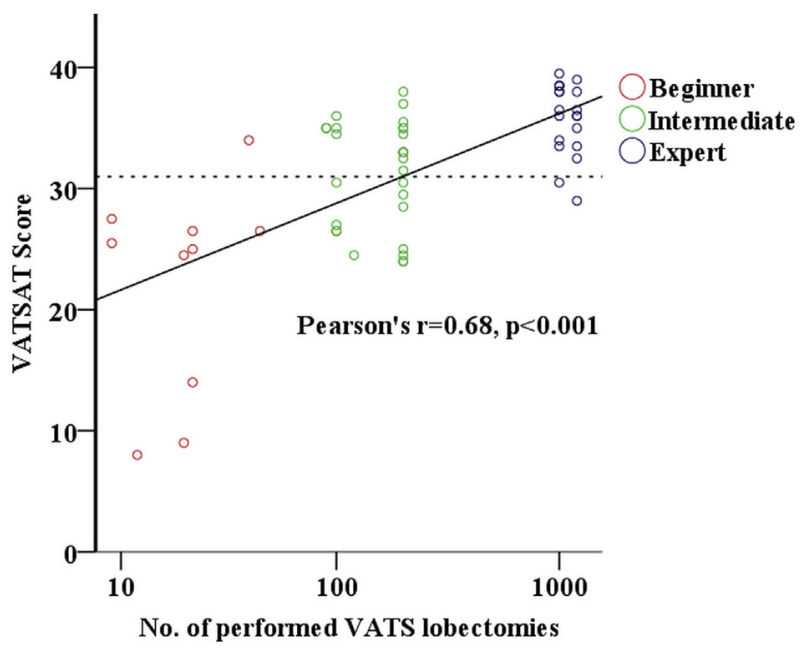

FIGURE 2. Logarithmic relation between the number of VATS lobectomies performed $(\mathrm{n}=58)$ and the VATSAT score. Red dots represent VATSAT scores for beginners, green dots represent VATSAT scores for intermediates, and blue dots represent VATSAT scores for experts. Black dotted line is the pass/fail ratio of 31. VATS, Video-assisted thoracic surgery; VATSAT, video-assisted thoracoscopic surgery lobectomy assessment tool. 


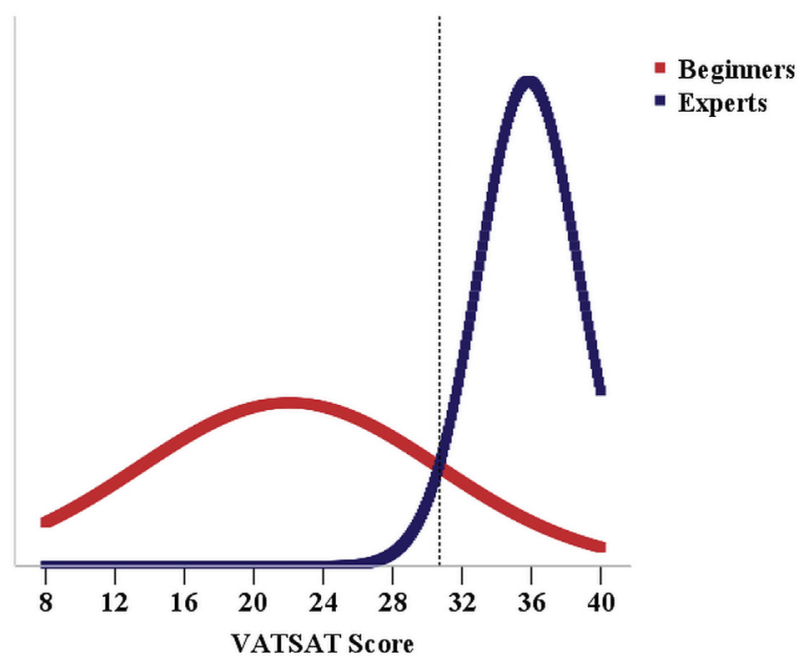

FIGURE 3. Pass/fail VATSAT score assessed using the contrasting group's method for beginners ( $r e d, \mathrm{n}=10$ procedures) and expert thoracic surgeons (blue, $\mathrm{n}=20$ procedures). VATSAT, Video-assisted thoracoscopic surgery lobectomy assessment tool.

performed by experts 35.9 (SD, 2.9; range, 29.0-39.5); $P<.001$, presented as a box plot in Figure 1 .

ANOVA with Bonferroni post hoc tests revealed that mean scores for experts were significantly better than for intermediates and beginners $(P<.008$ and $P<.001$, respectively). Intermediates' mean scores were significantly better than beginners $(P<.001)$. The logarithmic relation between number of VATS lobectomies performed and the mean VATSAT score is shown in Figure 2. The Pearson's correlation is $\mathrm{r}=0.68(P<.001)$.

Evidence based on consequences of testing: The pass/fail mean standard calculated using the contrasting group's method was 31 points. One procedure performed by a beginner passed the test with a mean score of 34 (falsepositive), and 2 procedures performed by experts failed the test with mean scores of 29 and 30.5 points (false-negatives) (Figure 3).

\section{DISCUSSION}

Validity evidence has been demonstrated for the VATSAT used in a simulated environment. ${ }^{15}$ In this study, validity evidence for the VATSAT used in a clinical situation with live surgical cases from 4 different centers being video recorded and the raters blinded for the institution and the surgeon is demonstrated.

Our group has previously published an assessment tool targeted toward VATS wedge resections, but VATSAT is the first assessment tool developed specifically to assess VATS lobectomy. ${ }^{19}$ A systematic review published in 2015 identified 29 articles focused on procedural tasks. The majority of studies addressed tasks related to general surgery and the remaining to obstetrics/gynecology, vascular surgery, orthopedics, cardiac surgery, plastic surgery, and minor surgical procedures by family physicians. ${ }^{20}$ Minimally invasive thoracic surgery and perhaps especially VATS lobectomies are highly specialized procedures, and there is a need for dedicated assessment tools. $^{21}$

The total internal consistency reliability Cronbach's alpha of 0.93 shows that the 8 items in the VATSAT measure the same trait and thereby provides evidence for the well-aligned content of the tool. A high Cronbach's alpha indicates a strong correlation among the 8 individual items in the VATSAT. Surgeons who have a high score high in 1 item also have a high score in the other items. ${ }^{22}$ This internal consistency reliability is similar to what have been demonstrated for the Global Operative Assessment of Laparoscopic skills that were developed by Vassiliou and colleagues ${ }^{23}$ in 2005 . They found an internal consistency reliability of 0.91 to 0.93 by assessing 21 participants performing laparoscopic cholecystectomies by 2 trained observers present in the operating room and by the attending surgeon assisting the procedures.

In our study, the inter-rater reliability between the 2 blinded raters at a Pearson's $r$ of 0.71 was highly significant $(P<.001)$, meaning that there was a significant agreement in the total score between the 2 raters. An inter-rater reliability in the range of 0.70 to 0.79 may be applied for formative assessments such as feedback after a completed training course. For moderate stake summative assessments as end of year examination in medical school, an inter-rater reliability between 0.80 and 0.89 is expected. High stake tests as a board certification and licensure require inter-rater reliability greater than $0.90 .^{22}$ The inter-rater reliability can be improved by increasing the number of rated procedures per surgeon or by increasing the number of raters. ${ }^{24}$ Our results clearly show that certification aided by VATSAT scores should be based on assessment of more than 1 procedure per trainee.

Rating of VATS lobectomy is a time-consuming task, and the use of a VATS specialist is costly. Therefore, it is important that a potential test does not need too many raters. The use of video recordings has several advantages compared with direct observation in the operating room that will always be prone to bias. A previous study showed that direct observation favored operators well known by the rater or considered competent because of their position. ${ }^{25}$ Another advantage of video recordings is that the VATS expert rater can schedule the rating to an appropriate time and place. ${ }^{26}$ Using nonexperts or novice raters may be considered, because the availability is easier and the costs are less. This approach should be used with some caution, but recent work has shown good inter-rater reliability between expert and nonexpert raters. ${ }^{27,28}$

The logarithmic relation between the experience level of the thoracic surgeons and the mean VATS score shows good 
consistency. However, a Pearson's correlation of $r=0.68$ $(P<.001)$ is not a perfect correlation. Figure 1 shows that it is not possible to precisely predict competence on the basis of the VATSAT score from a certain experience level; for example, a threshold of 50 procedures will not ensure that all surgeons are competent. The VATSAT score is increasing with increasing experience level, and at the same time the variance in performance is decreasing (Figure 3). This is in accordance with the model for skills acquisition by Fitts and Posner: Performance is variable in the beginning of the learning process, but as the performance improves the variability also decreases and the performance characteristics become more similar. ${ }^{29}$ The use of volume cutoff to determine the beginner, intermediate, and expert surgeons is not ideal, but a necessary step at this point.

The VATSAT test was able to discriminate between expert surgeons and surgeons with an intermediate experience and between intermediates and beginners using the ANOVA with Bonferroni post hoc test, and this was highly significant $(P<.008$ and $P<.001$, respectively). In the simulation study, we were not able to discriminate between intermediate surgeons and expert surgeons. This may be due to the challenging and perhaps impossible task to make simulators reflect every aspect of real live surgery. ${ }^{30}$ The pass/fail standard of 31 points, calculated using the contrasting groups' method, established good validity evidence for consequences. ${ }^{31}$ One of the beginners passed the test and 2 of the experts failed the test. In a simulation study case, difficulty can be standardized. ${ }^{30}$ Other studies with live surgical procedures have tried to reduce the effect of disease and patient variability. ${ }^{32}$ This was not possible because of the nationwide design in this study. VATS lobectomies were heterogeneous in terms of difficulty level, and a considerable bias may reflect the variation observed. This underlines the point of basing important decisions on more than 1 procedure; even a beginner can do okay with a very easy patient, and competency cannot be determined on the basis of a single case.

The strengths of this study are the nationwide participation of thoracic surgeons from all departments of thoracic surgery in Denmark. This adds to the generalizability of our findings. Having 18 thoracic surgeons perform 60 VATS lobectomies reduced construct underrepresentation. The fact that we were able to show a highly significant discrimination of experts, intermediate surgeons, and beginners with only 2 raters is an important finding indicating that the VATSAT may aid in training and credentialing of VATS surgeons.

\section{Study Limitations}

Limitations of the study and a threat to validity evidence of the assessments may be construct-irrelevant variance in the form of rater errors. Raters may express restriction of range in their rating. ${ }^{33}$ None of the participating expert surgeons scored the mean maximum of 40 , and only 1 of the beginners scored the mean minimum score of 8 . Although the raters were blinded, we cannot rule out the possibility that special instruments or certain movements were recognizable. Therefore, possible identification of a center or individual surgeons may have biased the raters. It is important to emphasize that the focus was technical skills. Nontechnical skills are important and may interfere with the overall performance, ${ }^{34,35}$ but this was not captured in the current study.

\section{CONCLUSIONS}

Validity evidence was provided for a newly developed assessment tool for VATS lobectomy (VATSAT) in a clinical setting with 18 surgeons representing all thoracic units in Denmark based on video recordings of 60 VATS lobectomies and 2 blinded raters. Internal consistency reliability was high, and inter-rater reliability acceptable. The discriminatory ability among expert surgeons, intermediate surgeons, and beginners was highly significant with a pass/fail standard of 31 points. One of the beginners passed the test (false-positives), and 2 experts failed the test (false-negatives). We believe that the VATSAT can be a valid and important tool to aid in deciding when thoracic surgeons are competent to perform VATS lobectomies.

\section{Conflict of Interest Statement}

R.H.P. and H.J.H. have received speaker honoraria from Medtronic. All other authors have nothing to disclose with regard to commercial support.

The authors thank the participating surgeons and theatre staff at the departments of Cardiothoracic Surgery at Odense University Hospital, Aarhus University Hospital (Skejby), Aalborg University Hospital, and Copenhagen University Hospital (Rigshospitalet) for their thoughtful input and support to the study.

\section{References}

1. World Health Organization. WHO Media Center. Available at: http://www.who. int/mediacentre/factsheets/fs297/en/. Accessed January 2, 2018.

2. Rosen JE, Keshava HB, Yao X, Kim AW, Detterbeck FC, Boffa DJ. The natural history of operable non-small cell lung cancer in the national cancer database. Ann Thorac Surg. 2016;101:1850-5.

3. Detterbeck FC, Lewis SZ, Diekemper R, Addrizzo-Harris D, Alberts WM. Executive summary: diagnosis and management of lung cancer, 3rd ed: American College of Chest Physicians evidence-based clinical practice guidelines. Chest. 2013;143(5 Suppl):7S-37S.

4. Bendixen M, Jørgensen OD, Kronborg C, Andersen C, Licht PB. Postoperative pain and quality of life after lobectomy via video-assisted thoracoscopic surgery or anterolateral thoracotomy for early stage lung cancer: a randomised controlled trial. Lancet Oncol. 2016;17:836-44.

5. Falcoz PE, Puyraveau M, Thomas PA, Decaluwe H, Hürtgen M, Petersen RH, et al. ESTS database committee and ESTS minimally invasive interest group video-assisted thoracoscopic surgery versus open lobectomy for primary non-small-cell lung cancer: a propensity-matched analysis of outcome from the European Society of Thoracic Surgeon database. Eur J Cardiothorac Surg. 2016;49:602-9. 
6. Petersen RP, Pham D, Burfeind WR, Hanish SI, Toloza EM, Harpole DH Jr, et al Thoracoscopic lobectomy facilitates the delivery of chemotherapy after resection for lung cancer. Ann Thorac Surg. 2007;83:1245-9.

7. Whitson BA, Groth SS, Duval SJ, Swanson SJ, Maddaus MA. Surgery for early-stage non-small cell lung cancer: a systematic review of the video assisted thoracoscopic surgery versus thoracotomy approaches to lobectomy. Ann Thorac Surg. 2008;86:2008-18.

8. Decaluwe H, Petersen RH, Hansen H, Piwkowski C, Augustin F, Brunelli A, et al. ESTS Minimally Invasive Thoracic Surgery Interest Group (MITIG). Major intraoperative complications during video-assisted thoracoscopic anatomical lung resections: an intention-to-treat analysis. Eur J Cardiothorac Surg. 2015; 48:588-99.

9. Petersen RH, Hansen HJ. Learning thoracoscopic lobectomy. Eur J Cardiothorac Surg. 2010;37:516-20.

10. Petersen RH, Hansen HJ. Learning curve associated with VATS lobectomy. Ann Cardiothorac Surg. 2012;1:47-50.

11. McKenna RJ Jr. Complications and learning curves for video-assisted thoracic surgery lobectomy. Thorac Surg Clin. 2008;18:275-80.

12. Yan TD, Cao C, D’Amico TA, Demmy TL, He J, Hansen H, et al; International VATS Lobectomy Consensus Group. Video-assisted thoracoscopic surgery lobectomy at 20 years: a consensus statement. Eur J Cardiothorac Surg. 2014; 45:633-9.

13. Barsuk JH, Cohen ER, Feinglass J, McGaghie WC, Wayne DB. Residents procedural experience does not ensure competence: a research synthesis. J Grad Med Educ. 2017;9:201-8.

14. Dearani JA, Gold M, Leibovich BC, Ericsson KA, Khabbaz KR, Foley TA, et al. The role of imaging, deliberate practice, structure, and improvisation in approaching surgical perfection. J Thorac Cardiovasc Surg. 2017;154: $1329-36$.

15. Jensen K, Petersen RH, Hansen HJ, Walker W, Pedersen JH, Konge L. A novel assessment tool for evaluating competence in video-assisted thoracoscopic surgery lobectomy. Surg Endosc. March 30,2018 [Epub ahead of print].

16. Day J, Bobeva M. A generic toolkit for the successful management of delphi studies. Electron J Bus Res Methods. 2005;3:103-16.

17. Downing SM, Yudkowsky R. Assessment in Health Professions Education. New York, NY: Routledge; 2009.

18. American Educational Research Association, American Psychological Association, National Council on Measurement in Education. Standards for Educational and Psychological Testing. Washington, DC: American Educational Research Association; 1999.

19. Konge L, Lehnert P, Hansen HJ, Petersen RH, Ringsted C. Reliable and valid assessment of performance in thoracoscopy. Surg Endosc. 2012;26:1624-8.

20. Hatala R, Cook DA, Brydges R, Hawkins R. Constructing a validity argument for the objective structured assessment of technical skills (OSATS): a systematic review of validity evidence. Adv Health Sci Educ. 2015;20:1149-75.
21. Ferguson MK, Umanskiy K, Warnes C, Celauro AD, Vigneswaran WT, Prachand VN. Robot training in minimally invasive lobectomy: thoracoscopic versus robotic approach. Ann Thorac Surg. 2014;97:1885-92.

22. Downing SM. Reliability: on the reproducibility of assessment data. Med Educ. 2004;38:1006-12.

23. Vassiliou MC, Feldman LS, Andrew CG, Bergman S, Leffondré K, Stanbridge D, et al. A global assessment tool for evaluation of intraoperative laparoscopic skills. Am J Surg. 2015;190:107-13.

24. Konge L, Annema J, Clementsen P, Minddal V, Vilmann P, Ringsted C. Using virtual-reality simulation to assess performance in endobronchial ultrasound. Respiration. 2013;86:59-65.

25. Vogt VY, Givens VM, Keathley CA, Lipscomb GH, Summitt RL. Is a resident's score on a videotaped objective structured assessment of technical skills affected by revealing the resident's identity? Am J Obstet Gynecol. 2003;189:688-91.

26. Konge L, Vilmann P, Clementsen P, Annema JT, Ringsted C. Reliable and valid assessment of competence in endoscopic ultrasonography and fine-needle aspiration for mediastinal staging of non-small cell lung cancer. Endoscopy. 2012;44:928-33.

27. Mahmood O, Dagnæs J, Bube S, Rohrsted M, Konge L. Nonspecialist raters can provide reliable assessments of procedural skills. J Surg Educ. 2018;75:370-6.

28. Lendvay TS, White L, Kowalewski T. Crowdsourcing to assess surgical skill. JAMA Surg. 2015;150:1086-7.

29. Magill R, Anderson D. Motor Learning and Control Motor Learning and Control: Concepts and Applications. 10th ed. New York: McGraw-Hill Education; 2015.

30. Jensen K, Bjerrum F, Hansen HJ, Petersen RH, Pedersen JH, Konge L. A new possibility in thoracoscopic virtual reality simulation training: development and testing of a novel virtual reality simulator for video-assisted thoracoscopic surgery lobectomy. Interact Cardiovasc Thorac Surg. 2015;21:420-6.

31. Norcini JJ. Setting standards on educational tests. Med Educ. 2003;37:464-9.

32. Aggarwal R, Grantcharov T, Moorthy K, Milland T, Darzi A. Toward feasible, valid, and reliable video-based assessments of technical surgical skills in the operating room. Ann Surg. 2008;247:372-9.

33. Iramaneerat C, Yudkowsky R. Rater errors in a clinical skills assessment of medical students. Eval Health Prof. 2007;30:266-83.

34. Gjeraa K, Mundt AS, Spanager L, Hansen HJ, Konge L, Petersen RH, et al. Important non-technical skills in video-assisted thoracoscopic surgery lobectomy: team perspectives. Ann Thorac Surg. 2017;104:329-35.

35. Gjeraa K, Spanager L, Konge L, Petersen RH, Østergaard D. Non-technical skills in minimally invasive surgery teams: a systematic review. Surg Endosc. 2016;30: 5185-99.

Key Words: VATS, video-assisted thoracoscopic surgery, lobectomy, assessment tool, education, learning 